\title{
Narrativas de representación en el cine de autor latinoa- mericano: Buenos Aires Viceversa, la crítica y los recur- sos de análisis
}

\author{
Patricia Adriana Delponti | pdelponti@ull.edu.es \\ Universidad de La Laguna
}

Carmen Rodríguez Wangüemert | crodrigu@ull.edu.es

Universidad de La Laguna

\author{
Palabras clave \\ "Argentina”; "recursos simbólicos" \\ Sumario \\ 1. Introducción \\ 2. Marco teórico \\ 3. Metodología \\ 4. Resultados \\ 4.1 Punto de ignición \\ 4.2 Descomposición Lineal \\ 4.3 Estratificación \\ 5. Discusión: \\ 5.1 Enumeración y orden \\ 5.2 Forma y contenido innovador \\ 6. Conclusiones \\ 7. Bibliografía
}

"Representación"; "cine"; "autor"; "análisis";

\section{Resumen}

Como aporte para ahondar en las narrativas de representación de Latinoamérica y sus países, este artículo pretende reforzar el valor del análisis crítico cinematográfico, explorar las mixturas que se produjeron en el tránsito del documental a la ficción, en el Nuevo Cine Latinoamericano. Además de mostrar cómo la película Buenos Aires Viceversa (Agresti, 1996), logra construir un pasado representado que ofrece recursos simbólicos inequívocos sobre Argentina. La metodología empleada se estructura en tres etapas, una contextual de revisión de la literatura, seguida de un trabajo de documentación que estudia cómo se ha

ocupado de la representación el análisis de la crítica especializada. Por último, se analiza Buenos Aires Viceversa, con un modelo que sitúa a la obra entre el cuerpo creador y el público. Como resultado de dicho análisis, la película se reafirma como un texto precursor de las tendencias audiovisuales latinoamericanas, con una estructura de narraciones concéntricas: las fragmentaciones en la representación de la ciudad (espacio); la de los hijos de desaparecidos de la dictadura (personajes), quienes, sin poseer una memoria factual (historia), se hallan en edad de cuestionamientos y participan en el proceso de ofrecer al público formas concretas de las ideas abstractas que el autor elige proyectar.

\section{Cómo citar este texto:}

Patricia Adriana Delponti y Carmen Rodríguez Wangüemert (2021): Narrativas de representación en el cine de autor latinoamericano: Buenos Aires Viceversa, la crítica y los recursos de análisis, en Miguel Hernández Communication Journal, Vol. 12(2), pp. 423 a 443. Universidad Miguel Hernández, UMH (Elche-Alicante). DOI: 10.21134/mhjournal. v12i.1335 
Representative narratives in Latin American auteur cinema: Buenos Aires Viceversa, the critic and the analysis resources

Patricia Adriana Delponti | pdelponti@ull.edu.es

Universidad de La Laguna

Carmen Rodríguez Wangüemert | crodrigu@ull.edu.es

Universidad de La Laguna

Keywords

"representation"; "cinema”; "auteur"; "analysis";

"Argentina”; "symbolic resources".

Summary

1. Introduction

2. Theoretical framework

3. Methodology

4. Results:

4.1. Ignition Point

4.2. Linear decomposition

4.3 Stratification

5. Discussion

5.1 List and order

5.2 innovative form and content

6. Conclusions

7. References

\section{Abstract}

As a contribution to the research on auteur cinema in Latin-American's countries, reinforcing the value of critical film analysis and exploring the mixtures that took place in the transition from documentary to fiction in the New Latin American Cinema. The film Buenos Aires Viceversa (Agresti, 1996) manages to construct a represented past that offers unequivocal symbolic resources about Argentina. The methodology employed is structured in three stages: a contextual review of the literature, followed by a documentation work that studies how

the analysis of specialised critics has dealt with the representation. Finally, Buenos Aires Viceversa is analysed using a model that situates the work between the creative corpus and the audience. As a result, the film is reaffirmed as a precursor text of Latin American audiovisual trends, with a concentric narrative structure: fragmentations in representing the city (place); the children of the dictatorship missing people (characters), who, without having a factual memory (history), are in an age of questioning and participate in the process of offering the audience concrete forms of the abstract ideas that the author chooses to project.

Patricia Adriana Delponti y Carmen Rodríguez Wangüemert (2021): Narrativas de representación en el cine de autor latinoamericano: Buenos Aires Viceversa, la crítica y los recursos de análisis, en Miguel Hernández Communication Journal, Vol. 12(2), pp. 423 a 443. Universidad Miguel Hernández, UMH (Elche-Alicante). DOI: 10.21134/mhjournal. v12i.1335 


\section{Introducción}

Dentro de los estudios de la representación de las sociedades, las narrativas del cine y el cine de autor destacan en Latinoamérica. La representación que se hace desde la industria cultural del cine se materializa en una construcción mediada en la que la realidad trasladada y/o simbólica se generaliza y expande para construir imaginarios que hoy en día tienen un alcance y proyección virtual masiva y global. Esto produce un incremento de lo que se ha se ha convenido en denominar movilidad psíquica de la mirada del otro que caracteriza a las sociedades postindustriales (Marín, 2002, 2006).

La historiografía del cine latinoamericano, cuyo vasto desarrollo ha sido desigual a lo largo de los últimos 60 años, se ha visto intensificada y consolidada en términos cuantitativos y cualitativos (Hopfenblatt, 2017) desde el inicio del milenio gracias al desarrollo tecnológico que ha permitido trascender el alcance del marco regional y establecer intercambios con otras fuentes de investigación académica e instituciones transnacionales (Paranaguá, 2003, 2010). Así, el interés por examinar la producción cinematográfica de Latinoamérica y la expansión de las industrias cinematográficas locales, junto a las nuevas tendencias técnicas y el aumento de las co-producciones, han captado la atención de académicos y críticos que han dedicado sus investigaciones a explorar las películas menos conocidas de varios países (Vohnsen, 2020), entre ellos Argentina. La convergencia de estas investigaciones recae no sólo en la revisión histórica de las producciones (documentales y ficcionales) con orientación claramente social, política y desde una perspectiva anticapitalista, sino también en los estudios comparados sobre filmografías nacionales y en especial aquellas que examinan y reinterpretan las películas realizadas en torno a las dictaduras, así como aquellas que indagan en las representaciones de los procesos revolucionarios en América Latina (Lusnich, 2012).

La propuesta de la presente investigación estudia un caso que podría considerarse paradigmático en el sentido estético (con el uso de la fragmentación narrativa, interpelación al espectador y recursos retóricos como la metáfora y la alegoría)en esa tarea de revisar los efectos de la dictadura militar en Argentina, años después de recobrada la democracia e incentivar con ello, si cabe, el desarrollo de una conciencia provocadora sobre lo ocurrido, gracias al poder de penetración cultural ejercido por los códigos lingüísticos empleados por el cine en general y por el de autor en particular. Puede considerarse también paradigmático en la proyección del entorno y en comparación con el resto de producciones que durante la primera década de democracia, revisan la dictadura militar argentina alejadas de la estética del cine de autor (Delponti, 2008), pues se aborda el análisis de una película de Agresti, cuya singular estructura estético narrativa permite ahondar en la fuerza de representación de una época de transformación política y social fundamental en la historia reciente de Argentina y que pone en valor las bases de una forma del pasado, que sin duda ha influido en la composición cultural de la narración audiovisual actual. 
La herencia cultural y las diversas maneras en que se articula, se desarrolla, se modifica o se configura la perpetua interrogación de la condición humana en la realidad presente, tienen un testigo privilegiado en el caso propuesto y dicha dimensión testimonial y de permanente reconfiguración de la realidad, de acuerdo con la manera en que el individuo la recepta, puede considerarse la atribución más importante del juego del arte, cuya sustancia política se explicita en lo estético. Juego que, huelga decirlo, es extremadamente serio (Lacolla, 1998).

La película ha sido elegida por aportar símbolos suficientes como para que sea considerada como un ejemplo de la mezcla equilibrada entre lo referencial y la ficción que nutre los orígenes del Nuevo Cine Latinoamericano y del pasado representado de ese país sudamericano. Además, el análisis crítico que aquí se propone (Delponti, Rodríguez-Wangüemert, 2019), integra tanto el estudio de la obra como su crítica periodística de forma fusionada, para observar la manera de construcción del sentido a la realidad que representa. Así y en el marco de un "proceso receptivo adecuado, el texto estético aparece como un espacio de realidades posibles, de significados posibles", (Schmidt, 1971:45).

Buenos Aires Viceversa (Agresti, 1996), nos hace reflexionar sobre la importancia de la identidad y si bien la información pierde valor semántico después de 25 años desde su estreno, la obra habilita, en cambio, otras subtramas que invitan a refrescar la mirada acerca del papel del cine en la reconstrucción o representación del pasado. A las valoraciones críticas de la película se suma el análisis que se propone a modo de exploración en las narraciones concéntricas y que permiten reconocer el impacto de la obra. Existe mucha literatura acerca del texto (película) elegido, e incontables críticas periodísticas, muchas de ellas dedicadas a lo técnico-estético presente y destacado en la película. En nuestra investigación, acotamos la aplicación de un modelo de análisis crítico (Delponti, 2007), que coloca la obra en el centro y es a través de ella que se establecen las miradas y el diálogo entre el cuerpo creador, la crítica y el espectador. Desde una perspectiva cualitativa, partimos de las investigaciones que identifican el carácter de cine de autor y de creador de tendencia en la obra de Agresti.

\section{Marco teórico}

Se aborda el trabajo, a sabiendas de la latente discusión sobre la existencia o no, de un cine latinoamericano en sentido estricto (Paranaguá, 2003:23) y sobre la legitimación del cine de autor como género específico ante la contaminación de las estructuras hipertextuales- la discusión se aprecia ya tan solo como retórica - (Garriga Nogués, 2006; Delponti, 2007). Plantear un método de análisis crítico y validarlo con esta película, no obsta para hacer un recorrido contextual por los estudios que resaltan como precursora la etapa de la producción argentino-holandesa del director, que se adelanta en la disolución de la frontera entre géneros audiovisuales, "donde la omnipresencia de la imagen y la evolución constante del ecosistema mediático, son el caldo de cultivo perfecto para la hibridación ad infinitum de las taxonomías de la 
La filmografía de Agresti se encuentra encajada entre el cine político revolucionario y la generación del nuevo cine independiente a partir del Festival Bacifi de 1999, y "presenta un itinerario entre el cine político, el nuevo cine anti-industrial y el cine comercial de Agresti” (Berger, 2008). Destacan las críticas positivas de este texto frente a lo cuestionado de sus obras anteriores. La ciudad como marco y su visión fragmentaria, confieren un carácter especial a este film para la reflexión sobre la interacción sobre el pasado de la dictadura y el presente lleno de espacios públicos de anonimato saturados de sobremodernidad (Berger, 2008). La relación entre el pasado y el presente no queda explícitamente clara en la obra, que confronta a diferentes registros desde la ciudad y una exageración del desorden. Se contribuye a las coincidencias de diferentes estratos de la memoria, que es tema recurrente del cine argentino independiente de los 90.

Lo cierto es que después de 25 años desde su estreno, la versión de Agresti deja los interrogantes no solo en la crítica a la desmemoria, sino que "remite a una investigación incierta del pasado y su influencia en el presente que sobrepasa claramente un mero complejo de síntomas de la desmemoria en los tiempos del neoliberalismo" (Chappuzeau, 2016:353). Trasciende a la herencia de las generaciones: "aquello que corresponde a su historia que en parte no les es propia y con la que deben realizar algún tipo de trabajo psíquico plus, destinado a la elaboración de lo que las generaciones anteriores dejaron en suspenso" (Werba, 2002:297). No en vano, el texto está dedicado a los hijos de los 30 mil asesinados durante la dictadura militar (1976-83) y, junto al objetivo de ser contrapunto por sus técnicas, "muestra una visión coral y con un estilo que se construye como contrapunto entre los diferentes niveles de la diégesis y con una tendencia a la estética de testigo de la realidad no viable, pues todo enfoque supone una selección arbitraria de los hechos y estudiada, aunque en ocasiones pudiera entenderse como estructurada al azar" (Tompkins, 2001).

En el caso de la industria audiovisual latinoamericana, la influencia y supremacía de la carga documental sobre la ficción, está latente desde mediados de los noventa y es en la escritura de Agresti, donde se hace visible aquello que el Nuevo Cine Argentino proyectará después, a menudo como "herramientas de reivindicación y denuncia, [que] imprimen un carácter concreto y único al cine hecho en América Latina” (MartínezCano, Ivars-Nicolás y Roselló-Tormo, 2020:113).

[...] surgen una serie de autores que suponen un cambio en el perfil profesional: son cineastas vocacionales, que pasaron por la Universidad y, al mismo tiempo, se han curtido como profesionales del audiovisual en los más variados lugares. Presentan trabajos con un marcado carácter híbrido y una ruptura radical entre los géneros que, hasta ese momento, se daban por cerrados en lo periodístico y mediático (y no tanto en lo académico), como son el documental y la ficción (Blanco Pérez, 2021:65). 
Más allá de las controversias conceptuales, siguiendo la idea generalizada de que en el cine de autor el autor es la obra, lo que realiza se convierte en una nueva escritura, y, en casos como el de Agresti, en propuestas de nuevas tendencias de lo cinematográfico, no se detiene este trabajo en determinar el género. Partimos de la atribución ya existente de considerar la obra de autor y de vanguardia.

Salvamos la diferenciación controvertida entre la crítica y el análisis cinematográfico, que suscita la discusión académica y profesional; ya sea por las características de los nuevos medios (Iglesias, 2011); en parte por la crisis en la que están inmersos en el nuevo mundo de difusión digital, con su profusión de contenidos (Ruíz San Miguel y Ruiz Blanco, 2011), y en parte, por los cuestionamientos sobre la utilidad real de esos géneros desde la perspectiva de la industria cultural que, de alguna promueve la información condicionada al marketing (Heredero, 2011).

El análisis se considera en sí como una herramienta de trabajo que resulta útil y necesaria desde nuestra perspectiva. Así ha sido demostrado para ámbitos pedagógicos, y en los de aprendizaje de cine, aunque la valoramos como una fórmula multidisciplinar. La propuesta del análisis crítico se destina a las partes y sus interrelaciones, así como las relaciones entre el texto y el contexto en el que se mueve el contenido de la película. El análisis de una película es también una forma de teoría al construirse a través de los análisis basada en experimentación.

Frente a lo que sucede con la crítica en sí, los temas de una película, sus condiciones de creación y la interpretación de sus normas y valores no son parte del análisis específico, aunque estos elementos colaboren con su comprensión y contextualización. No existe el método universal de análisis de films (Aumont y Michel, 1990). Es importante crearse una herramienta propia, que luego se podrá adaptar a cada necesidad teórica. En cualquiera de los casos, el método de análisis ha de eludir los riesgos apuntados por Zunzunegui (2007): el fetichismo del dato empírico, el fetichismo del contexto y el retorno del biografismo. Además de evitar aportar solo una descripción de lo que ocurre en la película.

\section{Metodología}

El modelo propuesto (Delponti, 2007), valora descripción y análisis temático. La película se sitúa a medio camino entre el cuerpo creador y el público, pero acompañado del aparato estético y político-social de la crítica periodística, género principal del periodismo cultural.

Se parte del punto de ignición, que viene a ser el sitio exacto en donde el texto ilumina al espectador, donde la verdad apunta; lo que identifica el qué de todo el discurso. Todos los elementos de la película se tejen en torno a ese punto de ignición, desde el montaje como a elementos externos, como, por ejemplo, la crítica en los medios de comunicación. Ese punto de ignición no siempre es evidente a simple vista, puede no estar expreso, aunque siempre está inscrito de forma inconsciente, indecible o de 
manera simbólica.

Posteriormente, interesa lo que se denomina hecho fílmico, se le agrega otra confrontación de conceptos necesarios y lo son el hecho discursivo (contenido) y el hecho estético (forma), donde se acota bien el espacio de la forma; no importan tanto los significantes, sino la relación entre ellos y la manera en la cual surgen: la importancia recae en la esencia del proceso. Aparece, entonces, la noción de estética, que busca un concepto en el interior de la materia.

En función de alcanzar los objetivos del trabajo, se plantea la descomposición lineal de la historia en unidades narrativas, y se analizan transversalmente, en bloques de contenidos y secciones temáticas, donde las secuencias tienen un papel fundamental al objeto de poder indagar en las narrativas y su configuración posiblemente concéntrica en torno al punto de ignición. Luego, se enumerarán los segmentos definidos, según el orden de pertinencia alrededor de dicho eje temático central, dejando de lado la cronología del film y priorizando el flujo de situaciones y vínculos que confluyen en dicho eje. Es necesario explicitar las cuestiones técnicas de implicación simbólica y semiótica en relación con el punto de ignición y con el mensaje de la obra. También es importante aclarar que el grado de profundidad y exhaustividad vinculado al estudio de los aspectos estéticos, varía y guarda proporcional relación con el género al que pertenece la obra en cuestión, y con el objetivo y punto de vista del creador y el mensaje que intenta dejar en el espectador. Así, en términos de Schmidt, la relación existente entre el arte estético y la sociedad se da cuando el receptor experimenta su libertad en la comunicación estética, y puede desarrollar una conciencia crítica emancipadora para la constitución y modificabilidad de significados, instituciones y realidad (1971).

\section{Resultados}

\subsection{Punto de ignición}

La película hace reflexionar sobre la generación castigada por la dictadura militar argentina y sobre hallar felicidad en Buenos Aires, una ciudad de furia y anonimato. Parte de historias mínimas, pretexto para disparar situaciones diversas. Refiere a los hijos de desaparecidos, y a los herederos del sistema, en una sociedad fragmentada, alienada y egoísta.

Ofrece alternancia permanente de diversas subtramas, y usa una estética cinematográfica posmoderna que permite avanzar, retroceder, reflexionar, contrastar y volver a avanzar en las historias para proyectar así su particular visión sobre una Buenos Aires alienada, así la forma y el contenido, se corresponden con la fragmentación del nuevo orden urbano surgido a fines del siglo XX. Agresti intenta abarcar todo, a costa de desorden de trama y de obras que no parezcan acabar. 


\subsection{Descomposición lineal}

La estructura narrativa de Buenos Aires Viceversa es atípica, con un estilo particular de montaje que pareciera falta de planificación, y otorga con fragmentación un significado más sólido de espontaneidad e improvisación en la obra.

Hallamos cuatro unidades temáticas narrativas compuestas por las cuatro historias de mayor desarrollo en la pantalla. La interacción de los personajes de dichas cuatro historias (alguno agrupados en parejas), proyecta múltiples subtramas cotidianas de alto contenido significativo. Se unen en momentos precisos, sin que los personajes sean conscientes de los puntos en común de sus situaciones ni de las circunstancias.

Por un lado, está Daniela, hija de padres detenidos y desaparecidos, que deambula. Sin una identidad clara y con gran carencia de afecto, aspira a salir adelante con su vida. Por otro está Cristina, una mujer de mediana edad mentalmente inestable y atormentada por el ritmo de la vida cotidiana y la información que se difunde por televisión. Debido a su aparente patología psíquica, fantasea y cree que es la pareja del presentador del telediario, dialogando con el televisor como si fuese una persona. Luego aparece Damián, otro joven probablemente hijo de desaparecidos que también busca su lugar en la gran ciudad y aspira a mejorar sus condiciones económicas para abandonar la casa de los tíos, quienes se ocuparon de él. Por último y con un rol decisivo para el film surge el Bocha, un niño de la calle, huérfano como Daniela, que hace todos los esfuerzos por sobrevivir en una ciudad egoísta. Con afecto y alegría se une a Daniela para compartir la soledad y encontrar belleza en la vida que le toca.

\subsection{Estratificación}

Según la estructura narrativa mencionada, esta obra condensa, en cada pequeña historia, diferentes conflictos que se encuentran, de forma casi casual, en un momento concreto de la trama y a través de las cuales, se visibilizan las diferentes esferas de la realidad de una ciudad fragmentada y recompuesta a partir de voluntades anónimas. Estas características constantes en la filmografía de Agresti, son las que definen su estilo personal, reconocido por el aparato crítico de la época, que en la mayoría de las críticas revisadas sobre Buenos Aires Viceversa (Agresti, 1996) y otras obras del autor (España, 1997; García Oliveri, 1997; Scholz, 1997; Ravaschino, 1997 y Sendrós, 1997) aparecen referencias decisivas hacia los mecanismos narrativos del autor, las estructuras del relato, profundización en los perfiles psicológicos de los personajes e incluso aspectos autobiográficos que conforman un conjunto elementos que contribuyen a explicar el funcionamiento interno y coherencia de las obras de Agresti en general y la que estudia este trabajo, en particular. Las cuestiones técnicas forman parte también de toda la mirada que se realiza a la obra del autor. 


\subsubsection{Daniela y la soledad}

A través del personaje de Daniela, Agresti empieza a tejer la historia de la película en la se suceden una serie de representaciones de la ciudad. En ella se entrelazan de manera concéntrica las diferentes generaciones de personas corrientes que conforman el relato y representan la ciudad.

Daniela y Mario son una pareja de jóvenes que comparten momentos de pasión, pero sin involucrarse afectivamente. Daniela vive con sus tíos, tras la desaparición de sus padres, de quienes apenas conoce detalle. Pronto cumplirá 19 años y busca sobrevivir económicamente en una ciudad que pocas oportunidades brinda a la gente sin estudios. En permanente soledad, espera de Mario esa contención, ese albergue afectivo que no puede brindarle. Por su parte, Mario representa la incipiente burguesía potenciada en los noventa. Preocupado por las apariencias sociales, el estatus y el dinero, también se siente solo y se cobija en Daniela. La pareja se rompe, el joven cubre su soledad y se hace amigo de un aspirante a boxeador profesional que incorpora al relato los sueños de triunfo de la clase obrera urbana, que sueña con fama y dinero.

Daniela conoce luego a una pareja de abuelos quienes, traumados con la desaparición de su hija durante la dictadura, no salieron más a la calle y solo reciben gente en su casa. Así han pasado diez años y encargan a Daniela el trabajo de grabar un video con imágenes de la calle, lo que sucede en el día a día. Necesitan que se les cuente cómo es la ciudad, cómo está la gente. Daniela necesita dinero y acepta la oferta, por lo que empieza a mirar la ciudad desde otra perspectiva, con mayor sensibilidad y se esfuerza por encontrar momentos y escenas interesantes para registrar con su cámara. A partir del momento en el que se pregunta "dónde se puede encontrar belleza en esta puta ciudad" la película da un giro importante y pasa de la mostración a la reflexión, el ritmo aminora su marcha y si bien los hechos suceden con dinamismo y con una estética fragmentada que complica la linealidad de las subtramas, se logra instaurar la inquietud y el vacío como provocadores estímulos que inevitablemente apuntan al espectador.

Al finalizar, aparece el Bocha, un niño de la calle con quien Daniela establece amistad y comparte su soledad, lo poco que tiene; se acompañan y apoyan mutuamente.

\subsubsection{Cristina, loca por la televisión}

La historia de Cristina da lugar a otras subtramas afluentes que completan el filme. Mujer de mediana edad, que vive sola en su apartamento y su día transcurre en torno a una fantasía. Cree tener una relación con el periodista que presenta el telediario regional. Cocina para él, se aprende las noticias que difunde sin juicio sobre los temas que tratan y no mantienen otras relaciones sociales. Podría interpretarse como claro reflejo de la alienación que puede ejercer la gran ciudad, donde nadie se conoce, ni se interesa por los demás. 
Los acontecimientos ocurren de forma cotidiana, se anuncian por los medios, pero el ritmo de vida continúa igual. Una avería de su televisor hace surgir una pequeña historia paralela que iniciará con el técnico electrónico, con quien aparenta establecer una relación, circunstancia que confunde más a Cristina. A su vez, el técnico lleva una vida más o menos normal, con necesidades económicas y afectivas manifiestas, pero con expectativas acerca de lo que espera de la vida. Amigo de un filósofo, junto al que también trabaja en el servicio de reparaciones, reflexionan sobre sus realidades y sobre los viejos tiempos donde las relaciones sociales y las emociones se manifestaban con más pasión. Representan a esa generación desengañada y descontenta con la realidad que toca vivir en la ciudad.

En medio de esta amistad unida por la decadencia, surge una nueva mirada social, a través de una joven clienta que revela un pasar económico y social resuelto, pero no exenta de otra serie de tormentos, también producto de la alienación de la ciudad. A pesar de la belleza física y la economía boyante, la soledad y la falta de rumbo colectivo, se apropian también de este personaje urbano, confuso y posmoderno.

\subsubsection{Damián reflexiona y sobrevive}

Damián es otro personaje, también hijo de desaparecidos, que al igual que Daniela denota la necesidad de reforzar una identidad en una ciudad que no brinda muchas oportunidades de contención emocional y donde el ritmo vertiginoso en el que se producen los hechos, provoca que lo esencial de la vida pase ante los ojos de los habitantes sin ser advertido. Damián va en busca de otras posibilidades para mejorar su situación económica y para encontrarse a sí mismo, lejos de la familia con la que vive desde que sus padres fueron asesinados (sus tíos). En esa búsqueda se cierra en su individualidad, formando parte de esa masa social anónima que poco mira a su alrededor, pero son las diferentes circunstancias por las que atraviesa trabajando como conserje en un albergue transitorio, entre ellas descubrir a su tío sexópata y autoritario, las que hacen que reflexione y madure algunas estructuras afectivas personales.

\subsubsection{Bocha paga las consecuencias}

La forma en la que se le da muerte al niño, al final de la película, eleva al máximo el clima de tensión y dramatismo de la obra de Agresti. Todas las estructuras propias sobre las que está montada la trama se alteran por completo para centrarse en el significado final del film. Cada personaje toma conciencia, a su manera, de la realidad en la que vive. Daniela se hunde en la tristeza, Damián la consuela y descubre la realidad y el dolor de otros, Cristina abre los ojos ante lo sucedido y despierta de su locura, Mario observa lo que le parece increíble y el boxeador intenta hacer justicia con sus manos.

A pleno día, en una tarde cualquiera, todos los personajes confluyen casualmente en un centro comercial. Cada uno concentrado en sus preocupaciones y ajeno al resto de transeúntes, presencian la persecución de un policía loco y autoritario (tío de Damián) 
hacia un niño que intenta escapar, tras haber sustraído una cámara de vídeo de una tienda de electrónica, para filmar la realidad como lo hace su amiga Daniela. En medio del seguimiento, Bocha acorralado se para frente a unas cajas de cartón y es disparado en el estómago varias veces, cayendo al suelo completamente desprotegido delante de todas las personas que allí se encontraban.

Esta última escena, conjuntamente con aquella en la que el periodista narra los hechos de forma distorsionada e interesada, en el noticiero que ve Cristina, desencadenan la necesidad, en los personajes y en el espectador, de efectuar una reflexión sobre el destino de una sociedad alienada, manipulada por los medios de comunicación, castigada por la represión de la dictadura y por el sistema político - económico capitalista globalizado. Circunstancias que no potencian sino el individualismo y la pérdida de los valores esenciales, de manera constante e impune.

\section{Discusión}

\subsection{Enumeración y Orden}

En el siguiente diagrama están reflejados la mayoría de los elementos narrativos (personajes, narradores, espacio, contexto) que construyen y dan personalidad a la obra de Agresti, tanto los aspectos que invitan a la reflexión del espectador, como las sensaciones y sentimientos experimentados por los personajes a lo largo de toda la película. Estos enunciados pueden verse reflejados también en la crítica periodística publicada por la presa de la época y cuyo común denominador descansa en el estilo de su escritura fílmica caracterizada por las narrativas concéntricas y con escaso posicionamiento en contra de la obra.

La gran mayoría de las críticas analizadas, descubren las pistas para comprender el relato, otorgando al espectador datos externos al universo del film que permiten una recepción más comprometida con el mensaje e ideología subyacente en película. Sin embargo, ninguna de las estudiadas, dejan entrever una postura clara, respecto del contenido político implícito en la obra y mediante un discurso bastante conservador, los críticos evalúan las motivaciones y velocidad con la que Agresti radiografía los aspectos más esquizofrénicos y solitarios de la vida en una ciudad, aún marcada por la dictadura militar y el anonimato en el que la gran urbe sufre su pasado.

Los temas principales sobre los que gira el discurso crítico son la descripción y explicación sobre las condiciones de producción y de exhibición de la película de Agresti y de otras de su haber, al tiempo que sitúa al espectador en los detalles que explican las características del lenguaje cinematográfico empleado en Buenos Aires Viceversa, como también el papel del bajo presupuesto de producción y las temáticas poco habituales de las obras presentadas y premiadas en festivales internacionales. 
Figura 1: Enumeración y orden

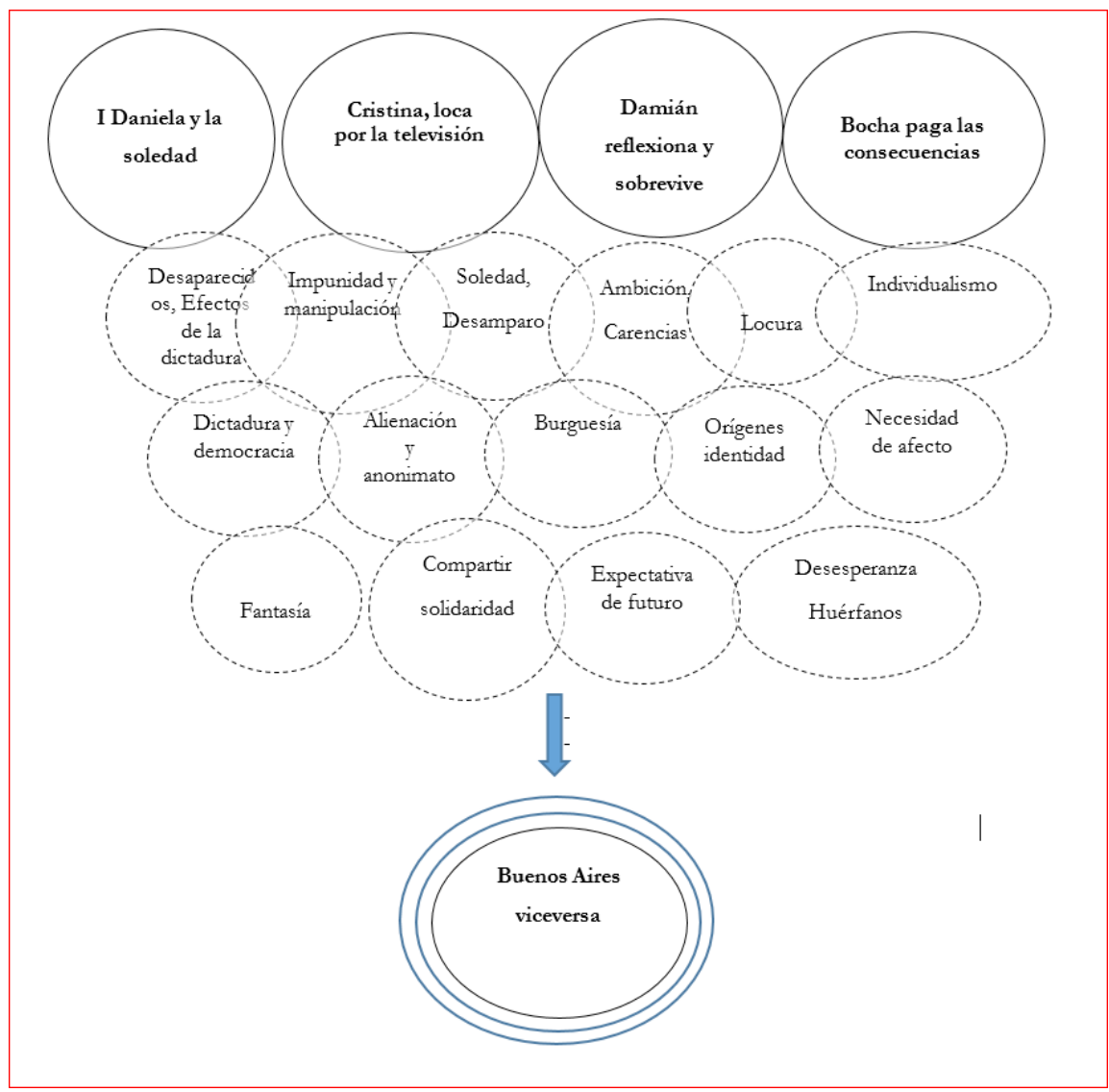

Fuente: elaboración propia, 2021

\subsection{Forma y contenido innovador}

Al igual que hizo en su obra previa titulada El amor es una mujer gorda, Agresti muestra una vez más su intrínseco interés por innovar. Con su particular estética, Agresti busca soltura en los relatos y espacios de imperfección, que distinguen su estilo del resto de realizadores de su generación y construye una obra poblada de costumbrismo en forma de collage audiovisual y atravesado por la experimentación y modernidad. La película está narrada de manera omnisciente y en ella, con diferentes miradas: la aspirada objetividad toma una porción de la realidad funcional, sin mediaciones aparentes. Sin embargo, los encuadres, planos imposibles, picados y contrapicados o los vertiginosos movimientos de cámara, no siempre justificados, complican el reconocimiento de la imagen, a la vez que ofrecen al espectador la 
posibilidad recorrer más libremente el significado de la obra.

Otro hallazgo a destacar del tipo de imágenes empleadas por Agresti se relaciona con la forma de propiciar la intimidad y cotidianeidad de los personajes, como el plano que deja ver cómo Mario se acomoda los aparatos de ortodoncia en su boca, cuando se lava los dientes o cuando Daniela se ajusta el sujetador mientras se viste. Éstos pequeños actos, que no forman parte del hilo conductor de la historia, son ejemplos del gran valor simbólico que Agresti representa sencillez y autenticidad de los que representa en los mínimos gestos de gente simple.

Para conseguir la verosimilitud deseada y transitar el camino entre la ficción y el documental, el autor recurre al empleo de importantes deslizamientos de cámara, travellings efectuados en la mayoría de las escenas, recurso que al seguir a los personajes en sus movimientos otorga a las secuencias más dinamismo y naturalidad. También resulta trascendente el rodaje sin trípode, claramente apreciable por los ligeros movimientos en las imágenes, especialmente en aquellas que están realizadas en exteriores como la calle y los parques, que muestran la saturación, el ritmo y la fragmentación de la realidad que se vive en la gran ciudad. Y esto se reafirma en la vocación de proponer con estos recursos técnicos, una mirada oblicua e innovadora sobre lo que sucede en la ciudad, libre de convenciones sobre la rutina del acontecer diario.

Frecuentes son también los planos rodados desde techos de edificios grises, con picados inesperados y desde ángulos considerablemente extraños y plenos de movimientos de cámara, que no quitan sencillez al estilo de la película. De pequeños actos, Agresti construye grandes y comprometidos significados basados en el amor y la memoria para resistir.

Abordando la iconicidad, Buenos Aires Viceversa contiene elementos de trascripción icónica claros sobre la forma de vida en la ciudad, mediante el vestuario, maquillaje y la apariencia general de las calles construyen el contexto y emociones de los personajes. En Daniela es representativa la imagen de orfandad y descuido que muestra con sus piernas sucias, lastimadas y su pelo sin arreglar, mientras almuerza sándwiches en los parques donde graba imágenes para su vídeo. Al igual que este personaje, cada uno de los otros actúa y mantiene una actitud consecuente con la intención del autor, que permite realizar un reconocimiento rápido de la ciudad y su estado, sus lugares emblemáticos y que caracterizan a un Buenos Aires difícil de digerir. Visibles son las miradas sobre el paseo Caminito del barrio de La Boca, las solitarias escaleras de diversos edificios, grises fachadas y azoteas anónimas.

Otro de los códigos tecnológicos muy presentes en la obra de Agresti es el manejo de la fotografía y su empeño en la luz neutra diegética y colores alterados. Los personajes se pueden reconocer a través de claroscuros, sombras y momentos en los que la luz natural desaparece, dificultando incluso la visualización de las escenas. Eso es parte también de la huella de la enunciación. Sin embargo, en los momentos de tensión, luz 
expresamente amarilla, otorgan a la historia el necesario dramatismo que pretende conseguir y el tono de luz azul empleado en la secuencia final, conjuga con la cámara lenta y en silencio, la peor escena de todas y que cerrará la historia con la muerte del niño.

Los desplazamientos de cámara a gran velocidad, los enfoques y desenfoques de acompañados de bruscos movimientos y el uso de la lenta en los momentos en los que se evoca la reflexión del espectador, se alternan en la película con imágenes fijas de niños sonrientes jugando en las plazas, como la otra cara de la ciudad que tímidamente existe.

Desde el punto de vista gráfico, la película arranca con una clara declaración de intenciones escrita en letra roja que dice: "En los años de la dictadura militar en la Argentina desaparecieron y fueron asesinadas unas 30.000 personas. La mayoría de ellas eran jóvenes y los hijos que dejaron recién hoy están en edad para pedir respuestas a la sociedad. A ellos está dedicado este film" (Buenos Aires Viceversa, 1996).

Otros paratextos funcionan como marcadores temporales y contextuales, como por ejemplo los carteles pegados en las fachadas de edificios con quejas sociales y pancartas que reivindican la manifestación popular que clama castigo para los culpables y justicia por los desaparecidos de la última dictadura militar. En dicha protesta es posible ver una representación teatral de un calabozo repleto de muñecos sin rostro, que simulan ser los asesinados durante el gobierno de facto.

Aparte de las figuras profílmicas que hay en la película, también es posible advertir otros mecanismos que indican el momento temporal, político y social que presenta el universo diegético; por ejemplo, la propaganda televisiva que efectúa el periodista que conduce el telediario, cuando hace referencia al bienestar y crecimiento del país en los últimos años e informa que actualmente se encuentra "en la curva ascendente". Ideas que contrastan con la miseria y tristeza que registra Daniela en sus grabaciones callejeras, como también con la imagen que muestra al filósofo Paolucci, amigo del técnico de TV, angustiado y con un cartel colgado de su pecho que dice: "yo no fui", ya que, tras haber retornado del exilio, aún precisa tiempo para asimilar la evolución que vivió su país.

Otro elemento a subrayar en este análisis es el empleo de los diferentes códigos sonoros naturales perceptibles en esta obra fílmica, que se alternan con el uso del silencio para crear atmósferas de tensión, dramatismo y reflexión. La mayoría de los sonidos son diegéticos y muchos de ellos son ecos típicos de los ruidos que se oyen en la calle, bullicio, el tren que pasa, el stress de la gente, coches circulando por las vías, etc. También es frecuente la utilización de música in que luego se convierte en over. Entre las melodías que dispone la obra se destacan los acordes de piano, guitarra y bandoneón que interpretan milongas, tangos y otros temas musicales populares de Buenos Aires, identificados como representativos de la época que se trata, como la Canción para mi muerte de Sui Géneris, algunos temas de Almendra, Luis Alberto 
Spinetta y Pescado rabioso.

Desde el punto de vista sintáctico, Buenos Aires Viceversa organiza las secuencias de manera cronológica, pero alternando los saltos argumentales y la evolución de las diferentes historias por separado. En algunos momentos puntuales los acontecimientos unen a los personajes, pero sin establecerse una relación demasiado profunda entre ellos, pese a lo que tienen en común. Aunque esta producción presente una estética narrativa fragmentada y aparentemente desconectada, la lógica interna del relato resulta coherente, y permite al espectador comprender el sentido de lo que ve. De hecho, la asociación de imágenes ya sea por contraste y o por transitividad está presente en las diversas secuencias que unen las historias sin correlato en torno al eje.

El contenido dramático de esta película está dado por los elementos trágicos que preceden a sus personajes y que dan sentido a toda la obra. Así, al final de la película y tras vivir los diferentes acontecimientos sucedidos, cada personaje logra elaborar un cierto grado de madurez o evolución en relación a la actitud frente a la vida y a la búsqueda de respuestas sobre la identidad.

La indirecta búsqueda de respuestas a las consecuencias de la dictadura militar, la necesidad de encontrar afecto y contención social en una ciudad anónima, saturada y alienante, conjuntamente con el incipiente ascenso de un aparato político capitalista y liberal que caracterizó la década de los noventa en Argentina, conducen al espectador a una profunda reflexión acerca de las razones de su existencia, del amor, la resistencia y la identidad como elementos fundamentales a recuperar para seguir viviendo.

El entorno político y social del universo diegético coincide con la realidad que vivió la ciudad de Buenos Aires en pleno mandato del presidente Menem, con la instalación del sistema liberal y de privatizaciones, que ya auguraban los efectos y la desigualdad en la sociedad argentina. Están presentes los símbolos del capitalismo más salvaje, con la irrupción de los centros comerciales y el estilo de vida burgués que contrasta con la situación de vida del colectivo inmigrante latinoamericano y de la nueva pobreza urbana. Las calles de la ciudad reflejan esas diferencias antes mencionadas, según las zonas que se trate y el estado emocional de la gente, el stress, la paranoia y la angustia son también indicadores del momento por el que atraviesa la historia de la película.

Buenos Aires Viceversa, es una obra en la que sus tramas se tejen a partir de planos autónomos y se articulan en sintagmas paralelos. Incluso podría decirse que no tiene un argumento concreto, sino varias historias que suceden de forma concéntrica en torno a la misma ciudad, donde los personajes se cruzan y comparten sensaciones, sin apenas advertirlo.

\section{Conclusiones}

Toda sociedad reflexiona sobre las causas profundas de sus conflictos, y el cine, tal y como han expuesto los autores referidos en el presente estudio, mantiene una vocación 
popular en esa necesidad de revisión histórica que también se da en Argentina. Por ello, Buenos Aires Viceversa, en su equilibrada conjugación icónico- lingüística, resulta pertinente en la representación de una parte importante de la historia de ese país ofreciendo una visión sobre la realidad que permite la reconstrucción de la misma; como ejercicio para mantener y solidificar la identidad. Ya lo aseguraba Bill Nichols cuando decía que "el realismo ofrece un acceso exento de problemas al mundo, a través de la representación física tradicional y de la transferencia fluida de estados psicológicos del personaje al espectador" (Nichols, 1997, p. 94).

Esto se da en un proceso en el que se reconoce al pueblo y a sus múltiples formas de expresión como los componentes esenciales y a la vez protagonistas y fines últimos de la liberación de las ideas. Esta liberación de las necesidades de una nación, implica también la emancipación y expansión de la cultura popular. La cultura nacional presente en la obra -en el sentido de nación- se define entonces por los valores, costumbres y las prácticas de un pueblo que necesitaba mirar al pasado para poder asimilarlo. Así se cimientan los procesos de identidad, autoconocimiento y memoria colectiva, así como una voluntad de progresar y transitar hacia el futuro. Un futuro que auguraba un renovado interés por la revisión de la noción de clases que constituyen las sociedades, cuya vigencia está quizás más viva ahora que nunca y esta experiencia social es constante en el cine latinoamericano contemporáneo (Vázquez- Vázquez, 2018).

A través del relato de los acontecimientos del pasado con una mirada claramente autoral y almacenados en la memoria popular, el cine de Agresti y concretamente Buenos Aires Viceversa, consigue hacerlos presentes. Contar la historia es hacerse responsable de los hechos a través del discurso y la enunciación histórica de los acontecimientos que encontramos en el film estudiado, es tangencial e independiente de su verdad objetiva. Así, "la ciudad moderna aparece en la película como un "no-lugar" cuya lógica repercute en el relato, el montaje, la elaboración plástica de los planos y el tratamiento del sonido". (Dufays, 2011: 615).

Desde la concepción semiótica, el cine se ve reforzado por convenciones necesarias a la hora de la construcción del relato, convenciones que no aparecían en el cine clásico, en el intento de borrar todo tipo de huellas que demarcaran lo no que no fuese natural, pero que están claramente presentes en Buenos Aires Viceversa, de hecho, no abandona el pacto establecido entre el texto y el referente histórico. Esta circunstancia supone entonces, una influencia en el espectador mucho mayor, dadas las representaciones construidas y transparentes de lo real y así se hace evidente en la crítica.

Por otra parte, tras el análisis crítico realizado concluimos que el modelo empleado resulta oportuno para su empleo en multiplicidad de ámbitos de conocimiento y muy en especial para el abordaje y enseñanza del cine como recurso pedagógico en los entornos educativos a diferente nivel. Nuestra propuesta, reivindica el reconocimiento de la materialidad del texto fílmico y la necesidad de centrarse en cómo dicen las películas lo que dicen (Zunzunegui, 2007). En esencia, el análisis que elegimos 
como análisis, huye de los principales peligros que el objeto de un análisis fílmico ha de eludir: del síntoma de un creciente fetichismo del dato empírico que afecta a buena parte de los trabajos analíticos e historiográficos más recientes (Zunzunegui, 2007:54). Apostamos, por tanto, por contribuir a los análisis textuales, definiciones de poéticas de autor e hipótesis acerca del cine realizado sobre la dictadura como fuente para la investigación, conocimiento y la reflexión histórica (Ferro, 1980; Alvira, 2011) y así poder "plantear una forma diferente de entender el devenir de la industria cinematográfica" (Kriger, 2010:4).

Apostamos más "por la hibridación generada a modo de ficción con tintes realistas" y también al revés, "cuando lo realista comienza a penetrar en un corpus netamente ficcional” (Blanco Pérez, 2021:63). También se sustrae el presente análisis de lo que se ha denominado el fetichismo del contexto porque cada obra da por sí algunas instrucciones sobre el contexto de comprensión: "Se trata de lo que los semiólogos denominan el «contexto pertinente de la interpretación». No hace falta agotarse en extraordinarias y laboriosas reconstrucciones de un contexto inabarcable, lo que habrá que reconstruir es la parte del contexto que la película me demande que actualice" (Zunzunegui, 2007:55).

La recuperación del esplendor y de la autenticidad de la realidad es lo que conduce al cine de Agresti y a esta película a ser el centro del debate sobre la reconstrucción identitaria argentina, poco más de una década después de recuperar la democracia; y esperándose de él, veinticinco años después, el rol de ser una ventana sobre esa identidad abierta al mundo o reflejo de éste.

\section{Bibliografía}

Alvira, P. (2011). El cine como fuente para la investigación histórica. Orígenes, actualidad y perspectivas. Revista Paginas, 3(4), pp. 135-152. https://doi.org/10.35305/ rp.v3i4.124

Aumont, J., Michel, M. (1990). Análisis del film. Paidós: Barcelona.

Berger, V. (2008). "La búsqueda del pasado desde la ausencia: Argentina y la reconstrucción de la memoria de los desaparecidos en el cine de los hijos", Quaderns de Cine. N. 3 pp. 23-36. https://doi.org/10.14198/QdCINE.2008.3.03

Blanco Pérez, M. (2021). New hybrid stories in Spanish fiction cinema. The case of Entre dos aguas by Isaki Lacuesta, Nuevos relatos híbridos en el cine de ficción español. El caso de Entre dos aguas de Isaki Lacuesta.: Ámbitos. Revista Internacional de Comunicación, (51), pp. 60-73. doi: 10.12795/Ambitos.2021.i51.04.

Chappuzeau, B. (2016). El desvío emocional frente a la memoria: 'Buenos Aires viceversa' (1996) de Alejandro Agresti. Romanische Studien, 0, pp. 339-354. 
Delponti Macchione, P. (2007a). Cómo analizar una película: a propósito de La Historia Oficial. Área Abierta, (18), pp. 1 - 15. Recuperado de https://bit.ly/3qVWp8p

- (2007b). Cine argentino en democracia, una mirada estético política a la dictadura militar de los 70: la crítica periodística cinematográfica. La Laguna: Universidad de la Laguna.

— y Rodríguez-Wangüemert, C. (2019). La crítica periodística y el análisis fílmico, una fusión integradora. Cultura y mediación en el cine argentino. Servicio editorial de la Universidad del País Vasco. Colección Comunicación

Dufays, S. (2011). El niño de la calle y la ciudad fragmentada en la película "Buenos Aires viceversa", de Alejandro Agresti. Hispanic Review, 79(4), pp. 615-637. Recuperado de https://bit.ly/2UxqG11

España, C. (1997). Agresti y un cine con alma de vecindario. Buenos Aires, La Nación, septiembre, pp.6..

Ferro, M. (1980). Cine e historia. Barcelona: Gustavo Gili.

García Oliveri, R. (1997). Igual que Arlt, pero en el cine, Buenos Aires, Clarín, junio, pp. 5.

García Oliveri, R. (1997). La juventud no tiene respiro, Buenos Aires, Clarín, septiembre, pp. 7.

Gubern Garriga-Nogues, R. (2006). La ingeniería del imaginario, del arte al espectáculo. DeSignis, Gedisa, Barcelona, octubre, pp. 19-26 y en Publicación de la Federación Latinoamericana de Semiótica. Recuperado de https://bit.ly/3jXWOFR

Heredero, C.F. (2011). Espacios de libertad, vigencia, defensa y necesidad de la crítica. En Vicerrectorado de Cultura y Deportes de la Universidad de Málaga (Ed.), El ejercicio crítico en el cine español. Primer Congreso de la Crítica. XIII Festival de Málaga. Cine Español (pp. 13-29) Málaga: Universidad de Málaga.

Iglesias, E. (2011). Crítica y análisis del film. Un acercamiento académico. n Vicerrectorado de Cultura y Deportes de la Universidad de Málaga (Ed.), El ejercicio crítico en el cine español. Primer Congreso de la Crítica. XIII Festival de Málaga. Cine Español (pp. 57-67). Málaga: Universidad de Málaga.

Kelly Hopfenblatt, A. (2017). Panorama sobre la situación de los estudios de cine en Argentina a partir del año 2000, Miguel Hernández Communication Journal, nº, pp. 19 a 50. Universidad Miguel Hernández, UMH (Elche-Alicante). https://doi.org/10.21134/ mhcj.v0i8.174

Kriger, C. (2010). Un recorrido bibliográfico por el cine argentino. Buenos Aires. 
Revista Imagofagia- Asociación Argentina de Estudios de Cine y Audiovisual. (ASAECA) N 2, Buenos Aires, octubre. Recuperado de https://bit.ly/3xtnqm5

Lacolla, E. (1998). El oficio de ver, Córdoba Argentina: Editorial Universidad Nacional de Córdoba.

Lusnich, A. L. (2012). Representación / Revolución. Ejes de la investigación. En Representación y revolución en el cine latinoamericano del período clásico-industrial: Argentina, Brasil, México, Serie Avances de Investigación no 73. Madrid: Fundación Carolina.

Martínez-Cano, F. J., Ivars-Nicolás, B., \& Roselló-Tormo, E. (2020). Cine memoria. Intersecciones entre documental y ficción en la práctica cinematográfica latinoamericana contemporánea: estudio de caso de Roma. Fotocinema. Revista Científica De Cine Y Fotografía, (20), pp. 111-136. https://doi.org/10.24310/Fotocinema.2020. $\underline{\mathrm{v} 0 \mathrm{i} 20.7594}$

Nichols, Bill. (1997). La representación de la realidad, cuestiones y conceptos sobre el documental. Barcelona: Paidós.

O Scholz, P. (1997). Se estrenan dos películas argentinas, Buenos Aires, Clarín, septiembre, pp. 6.

Paranaguá, P.A. (2003a). Tradición y modernidad en el cine de América Latina. Madrid: FCE.

- (2003b). Cine documental en América Latina. Madrid: Cátedra

- (2010c). Memoria e historia del cine en América Latina. Journal of Film Preservation N. ${ }^{\circ}$ 83, pp.: 16-22. Bruselas: Noviembre. Recuperado de https://bit.ly/3yJm4Uv

Ravaschino G. (1997). Buenos Aires Viceversa. Buenos Aires, Cineismo, septiembre, 9.

Ruiz San Miguel, F.J. y Ruiz Blanco, S. (2011). La crítica cinematográfica ante la crisis del periodismo y los nuevos medios sociales. El ejercicio crítico en el cine español. 29-56: Málaga.

Schmidt, S. (1971). Lo estético y lo político: la función de lo estético en el desarrollo social. Revista Hum-boldt año XII, N1/445, Hamburg, pp.11-20.

Sendrós D. (1997). Buenos Aires Viceversa. Buenos Aires, Criterio, septiembre, pp. 529.

Tompkins, C. (2001). Experimentación y concientización en Buenos Aires y Viceversa de Alejandro Agresti. Literatura e Autoritarismo, 4. (pp. 27-33). Universidad Federal de Santa María. Centro de Artes y Letras. Brasil. Diciembre, y en Academia.edu 
MHJournal Vol. 12 (2) | Año 2021 - Artículo no 20 (187) - Páginas 423 a 443 - mhjournal.org

Recuperado de https://bit.ly/3xvAven

VazquezVazquez, M.M. (2018). The Question of Class in Contemporary Latin American Cinema. London, Lexington Books.

Vohnsen, M. (2020). Latin American cinema. The Year's Work in Modern Language Studies 80, pp.432-453. doi:10.21427/dwrz-nr66

Werba, A. (2002). Transmisión entre generaciones: los secretos y los duelos ancentrales. Psicoanálisis, 24, Vol. XXIV, Buenos Aires, pp 295-313. Recuperado de https://bit. ly/3xzXq8I

Zunzunegui Díez, S. (2007). Acerca del análisis fílmico: el estado de las cosas. Comunicar, XV (29), Huelva, pp 51-58. Recuperado de https://bit.ly/3dZa6hv 


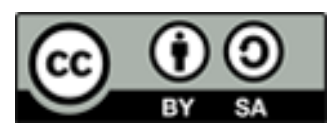

Licencia Creative Commons

Miguel Hernández Communication Journal

mhjournal.org

\section{Cómo citar este texto:}

Patricia Adriana Delponti y Carmen Rodríguez Wangüemert (2021): Narrativas de representación en el cine de autor latinoamericano: Buenos Aires Viceversa, la crítica y los recursos de análisis, en Miguel Hernández Communication Journal, Vol. 12(2), pp. 423 a 443. Universidad Miguel Hernández, UMH (Elche-Alicante). DOI: 10.21134/mhjournal. v12i.1335 